\title{
Degree of Hydration and Mass Balance Equations for Determination of Mix Proportion of Hardened OPC Concrete
}

\author{
Thidaporn Chuosavasdi ${ }^{1, a}$, Boonchai Stitmannaithum ${ }^{1}$, Taweechai Sumranwanich ${ }^{2}$, \\ Warangkana Saengsoy ${ }^{3, \mathrm{~b}, *}$, and Somnuk Tangtermsirikul ${ }^{4}$ \\ 1 Faculty of Engineering, Chulalongkorn University, Bangkok, Thailand \\ 2 Faculty of Engineering, Burapha University, Chonburi, Thailand \\ 3 Construction and Maintenance Technology Research Center (CONTEC), School of Civil Engineering and \\ Technology, Sirindhorn International Institute of Technology, Thammasat University, Patumthani, \\ Thailand \\ 4 School of Civil Engineering and Technology, Sirindhorn International Institute of Technology, \\ Thammasat University, Patumthani, Thailand \\ E-mail: athidaporn.ch@gmail.com, bwarangkana@siit.tu.ac.th (Corresponding author)
}

\begin{abstract}
A method for estimating mix proportion of hardened OPC concrete is proposed in this study. A set of mass balance equations was formed to calculate content of concrete compositions including cement, water, sand, and coarse aggregate. The degree of hydration of cement was taken into account in the analysis in order to cover the effect of age of concrete. In order to verify the accuracy of the proposed method, the determination of mix proportion of concrete was conducted on concrete specimens prepared in the laboratory with known mix proportions. Moreover, the mix proportion of concrete at different ages were calculated both with and without consideration of time-dependent degree of hydration in the analysis to clarify the enhanced capability of the proposed method when the effect of age of concrete is considered. It was found from the analytical results that the proposed method could be used to estimate mix proportion of concrete, with a satisfactory precision, at any age. The calculation of mix proportion of hardened concrete with consideration of time-dependent degree of hydration provided less error than that without consideration of the degree of hydration. The percentage of error of the mix proportion prediction of the concrete samples was less than $5 \%$.
\end{abstract}

Keywords: Mix proportion, hardened OPC concrete, selective dissolution, mass balance equations, degree of hydration.

ENGINEERING JOURNAL Volume 20 Issue 2

Received 6 July 2015

Accepted 26 October 2015

Published 18 May 2016

Online at http://www.engj.org/

DOI:10.4186/ej.2016.20.2.211 


\section{Introduction}

It is recognized that mix proportion of concrete influences mechanical and durability properties of the concrete. Some crucial parameters of concrete mix proportion are water to cement ratio $(w / c)$ and cement content. When a concrete structure is damaged, its concrete mix proportion is usually required for evaluation of durability and service life of the structures in order to assess the proper repair technique. However, the record of concrete mix design is often unavailable or not reliable even available, leading to a difficulty in correctly predicting the condition of the structure. Accordingly, the mix proportion of such concrete is necessarily examined after the concrete has been hardened.

Several techniques have been developed to identify mix proportion of hardened concrete. However, a promising method developed to identify the concrete mix design encompassing binder type, w/c, cement content and aggregate content does not exist. A number of studies have been devoted to determine either cement content [1-5] or w/c [4-8] of the concrete. Even though standards such as BS 1881: Part 124 [9] describe the methods for determining the cement content and other concrete compositions in the hardened concrete, each procedure requires a substantial degree of chemical skill and relatively complicated chemical instrumentation. Moreover, the existing methods are applicable merely for determining mix proportion of hardened concrete at long age (mature concrete) or at a specified age [10]. When these methods are applied for estimating mix proportion of hardened concrete at an arbitrarily early age, it may result in an inaccurate estimation.

A method for estimating mix proportion of hardened OPC concrete is proposed in this study. Both physical and chemical methods were adopted for the analysis. A set of mass balance equations was formed to calculate content of concrete compositions including cement, water, sand, and coarse aggregate. The degree of hydration of cement was also taken into account in the analysis in order to cover the effect of age of concrete. The determination of mix proportion of concrete has been conducted on concrete specimens prepared in the laboratory with known mix proportions in order to verify the accuracy of the proposed method. Moreover, the mix proportions of concrete at different ages were calculated both with and without consideration of time-dependent degree of hydration to clearly express the superiority of the proposed method when consider the effect of age of concrete.

\section{Experiment}

\subsection{Materials and Mix Proportion}

Cement concrete specimens were prepared in the laboratory with water to cement ratios (w/c) of 0.45 and 0.55. Ordinary Portland cement (OPC) type I was used. Chemical compositions of the cement are shown in Table 1. Specific gravity of cement is 3.15. Natural river sand and crushed limestone were used as fine aggregate and coarse aggregate, respectively. Specific gravity of the sand and the crushed limestone are 2.60 and 2.70, respectively. Mix design of concrete sample is shown in Table 2. Air content in the concrete is designed to be $1 \%$. The concrete specimens were prepared and cured for 14 and 91 days before being tested.

Table 1. Chemical composition of cement.

\begin{tabular}{cccccccccccc}
\hline $\begin{array}{c}\text { Chemical } \\
\text { Composition (\%) }\end{array}$ & $\mathrm{SiO}_{2}$ & $\mathrm{Al}_{2} \mathbf{O}_{3}$ & $\mathbf{F e}_{2} \mathbf{O}_{3}$ & $\mathbf{C a O}$ & $\mathbf{M g O}$ & $\mathbf{S O}_{3}$ & $\mathbf{N a}_{2} \mathbf{O}$ & $\mathbf{K}_{2} \mathbf{O}$ & $\mathbf{T i O}_{2}$ & $\mathbf{P}_{2} \mathbf{O}_{5}$ & $\mathbf{L O I}$ \\
\hline Cement Type I & 19.36 & 5.10 & 3.35 & 64.36 & 0.81 & 2.83 & 0.15 & 0.51 & 0.25 & 0.08 & 3.01 \\
\hline
\end{tabular}

Table 2. Mix design and age of testing of concrete samples.

\begin{tabular}{ccccccc}
\hline Sample & w/c & $\begin{array}{c}\text { Cement } \\
\left(\mathbf{k g} / \mathbf{m}^{3}\right)\end{array}$ & $\begin{array}{c}\text { Water } \\
\left(\mathbf{k g} / \mathbf{m}^{3}\right)\end{array}$ & $\begin{array}{c}\text { Sand } \\
\left(\mathbf{k g} / \mathbf{m}^{3}\right)\end{array}$ & $\begin{array}{c}\text { Coarse aggregate } \\
\left(\mathbf{k g} / \mathbf{m}^{3}\right)\end{array}$ & $\begin{array}{c}\text { Age } \\
(\mathbf{d a y s})\end{array}$ \\
\hline W45C & 0.45 & 407 & 183 & 776 & 1025 & 14,91 \\
W55C & 0.55 & 360 & 198 & 776 & 1025 & 14,91 \\
\hline
\end{tabular}




\subsection{Sample Preparation}

Cylindrical concrete specimens with a dimension of $10 \mathrm{~cm}$ in diameter and $20 \mathrm{~cm}$ in length were cast. A pan-type mixer was used to prepare concrete specimens in accordance with ASTM C192 [11]. Coarse aggregate, fine aggregate, and cement were loaded into the mixer and mixed thoroughly. Then, water was added with the mixer running. After all ingredients were in the mixer, continuously mixed for 3 min followed by a 2-min rest, and a 3-min final mixing until the concrete was homogeneous in appearance. After that the concrete was placed in the molds and compacted by an internal vibrator. The concrete specimens were removed from the molds at 24 hours after casting. The specimens were cured in water at room temperature until the specified test age. At each test age, three specimens were broken into small pieces and coarse aggregate was removed. The sample was immersed in acetone for 24 hours, then dried at $50^{\circ} \mathrm{C}$ in an oven to stop hydration reaction. After that, the sample was ground to the size smaller than 75 $\mu \mathrm{m}$ (No. 200 Sieve). The powdered sample was subsequently used for selective dissolution testing. Other two specimens at each age were prepared for examining unit weight of concrete according to ASTM C642 [12].

\subsection{Selective Dissolution Test}

The powdered sample was dissolved in the hydrochloric acid $(\mathrm{HCl})$. The $2 \mathrm{~N} \mathrm{HCl}$ was used to dissolve calcium components in cement and hydrated products. Further, the $5 \% \mathrm{Na}_{2} \mathrm{CO}_{3}$ was used to dissolve silica gel [13]. However, a few amount of cement was still insoluble. Therefore, the residues left from being dissolved were sand and a small amount of cement. The amount of residues from the selective dissolution test was subsequently used in a mass balance equation as in Eq. (3) for calculation of mix proportion of hardened concrete.

\section{Determination of Mix Proportion of Hardened Concrete}

The procedure for estimating mix proportion of hardened OPC concrete are divided into three parts consisting of determination of coarse aggregate content, determination of water to cement ratio $(\mathrm{w} / \mathrm{c})$, and determination of cement and sand contents. Coarse aggregate content is determined by image processing technique. Water to cement ratio can be calculated from data back analysis of the compressive strength by using the computer software, "FACOMP", which was developed at Sirindhorn International Institute of Technology (SIIT), Thammasat University, Thailand [14]. Models for predicting compressive strength of concrete, constructed based on experimental data, were implemented in the FACOMP. It has been proven that the prediction models could be used to accurately predict the compressive strength of concrete within acceptable limits $[15,16]$. It was confirmed from the previous study that both techniques were efficiently used to determine coarse aggregate content and $\mathrm{w} / \mathrm{c}$ [17]. Therefore, explanation on the determination of coarse aggregate content and w/c are not included in this paper. Cement and sand contents can be obtained based on the residues left from the selective dissolution test. Contents of all concrete compositions in $1 \mathrm{~m}^{3}$ of concrete can be derived from a set of mass balance equations. The proposed equations were applied to estimate mix proportions of concrete prepared in the laboratory with known mix design in order to verify efficiency of the proposed method. Moreover, the mix proportion of concrete at different ages were calculated both with and without consideration of time-dependent degree of hydration to clarify the enhanced capability of the proposed method when consider the effect of age of concrete.

\subsection{Calculation of Mix Proportion of Hardened Concrete}

Coarse aggregate content can be directly determined by image processing technique while water to cement ratio $(\mathrm{w} / \mathrm{c}$ ) can be obtained from data back analysis of the compressive strength as mentioned earlier. In order to determine contents of cement and sand in the sample, they were estimated primarily based on their oven-dried weight ratio. Equations. (1) and (2) were formed based on the mass balance condition of sample without coarse aggregate (mortar in the concrete). Equation (3) was formed based on the residues left from the selective dissolution test as mentioned in section 2.3. The equations were used to determine the weight ratio of cement and sand in sample without coarse aggregate $\left(w_{c s}\right.$ and $\left.w_{s s}\right)$. Effect of age of concrete was considered by incorporating the degree of hydration reaction in the calculation as in Eq. (2). 


$$
\begin{gathered}
w_{t s}=w_{c s}+w_{s s}+w_{n s} \\
w_{n s}=0.23\left(\alpha_{h y} w_{c s}\right) \\
r_{t s} w_{t s}=r_{c} w_{c s}+r_{s} w_{s s}
\end{gathered}
$$

where $r_{t s}$ is residual weight of sample (g/g of sample). $r_{c}$ is residual weight of cement ( $\mathrm{g} / \mathrm{g}$ of cement). $r_{s}$ is residual weight of sand (g/g of sand). $w_{t s}, w_{c s}, w_{s s}$ and $w_{n s}$ are ratio of oven-dried weight of sample, cement, sand, and combined water to oven-dried weight of the sample without coarse aggregate (mortar in the concrete), respectively. $w_{t s}$ is equal to $1 . \alpha_{h y}$ is degree of hydration of cement which can be obtained from mathematical models as shown in section 3.2. 0.23 is combined water for full hydration of cement $[6$, $18,19]$.

The weight ratio of cement and sand in sample without coarse aggregate can be obtained as mentioned earlier. The oven-dried weight ratio of cement and sand of concrete can be obtained by Eq. (4) and Eq. (5).

$$
\begin{gathered}
w_{t c}=w_{c c}+w_{s c}+w_{n c}+w_{G} \\
w_{G}=\frac{W_{G}}{\left(1+a_{G}\right) \times U W_{d}}
\end{gathered}
$$

where $w_{t c}, w_{c c}, w_{s c}, w_{n c}$ and $w_{G}$ are ratio of oven-dried weight of concrete sample, cement, sand, combined water, and coarse aggregate to oven-dried weight of concrete, respectively. $w_{t c}$ is equal to 1 . $W_{G}$ is aggregate content $\left(\mathrm{kg} / \mathrm{m}^{3}\right) \cdot \boldsymbol{a}_{G}$ is absorption of coarse aggregate. $U W_{d}$ is oven-dried unit weight of concrete $\left(\mathrm{kg} / \mathrm{m}^{3}\right)$ which can be obtained according to ASTM C642 [12].

Then, the oven-dried weight ratios of concrete compositions are converted to mass of cement, sand and water at SSD state as shown in Eq. (6) to Eq. (8).

$$
\begin{gathered}
W_{c c}=w_{c c} \times U W_{d} \\
W_{s c}=w_{s c} \times U W_{d} \times\left(1+a_{s}\right) \\
W_{w c}=W_{c c} \times(w / c)
\end{gathered}
$$

where $W_{c c}, W_{s c}$, and $W_{w c}$ are mass of cement, sand, and water of concrete at SSD state, respectively (kg). $a_{s}$ is absorption of sand. $\mathrm{w} / \mathrm{c}$ is water to cement ratio.

Generally, the mix design of concrete is estimated for $1 \mathrm{~m}^{3}$ of volume based on SSD state of the aggregates. Hence, volume of each concrete ingredient per 1000 liters of concrete is shown in Eq. (9). The volume of each concrete ingredient can be obtained by dividing its mass (Eq. (6) to Eq. (8)) by the specific gravity. Then, the content of cement, sand, and water of the mix proportion are obtained by Eq. (10) to Eq. (12).

$$
\begin{gathered}
V_{t}=1000=V_{c}+V_{s}+V_{w}+V_{G}+V_{a i r} \\
W_{c}=V_{c} \times S G_{c} \\
W_{s}=V_{s} \times S G_{s} \\
W_{w}=W_{c} \times(w / c)
\end{gathered}
$$

where $V_{t}, V_{c}, V_{s}, V_{w}, V_{G}$ and $V_{\text {air }}$ are total volume of concrete, cement, sand, water, coarse aggregate and air of concrete for 1000 liters at SSD state, respectively (liters $/ \mathrm{m}^{3}$ ). $S G_{c}, S G_{s}$ and $S G_{G}$ are specific gravity of cement, sand and coarse aggregate, respectively. $W_{c}, W_{s}$ and $W_{w}$ are mass of cement, sand, and water, respectively $\left(\mathrm{kg} / \mathrm{m}^{3}\right)$.

\subsection{Degree of Hydration of Cement}

The degree of hydration of cement was obtained from mathematical models constructed based on experimental data as in Eqs. (13) to (19). The models were implemented in a computer software [14]. The degree of hydration of cement was defined as the weight average of the degree of hydration of all compounds of the cement as shown in Eq. (13). 


$$
\alpha_{h y}(t)=\frac{\sum_{i=1}^{4} m_{i} \alpha_{i}(t)}{\sum_{i=1}^{4} m_{i}}
$$

where $\alpha_{h y}(t)$ is the degree of hydration of cement (\%). $\mathrm{i}$ is the mineral compound of cement $\left(C_{3} S, C_{2} S\right.$, $\left.C_{3} A, C_{4} A F\right) \cdot m_{i}$ is the mass of each compound per cubic meter of concrete $\left(\mathrm{kg} / \mathrm{m}^{3}\right) \cdot \alpha_{i}(t)$ is the degree of hydration (\%) of each compound in cement [20]. And, the degree of hydration of each cement compound at each constant concrete temperature can be formulated as a function of water to binder ratio and age as shown in Eq. (14) to Eq. (17). A, B, C, D, E, F, G and H in these equations are the constant values [21]. The physical acceleration at early age mainly affects the hydration reaction at early age of $C_{3} A$ and $C_{3} S$. The effect of physical acceleration of $C_{3} A$ and $C_{3} S$ is represented by $\eta_{C_{3} A}$ and $\eta_{C_{3} S}$, respectively [22]. The factors are shown in Eq. (18) and Eq. (19).

$$
\begin{gathered}
\alpha_{C_{3} A}(t)=\eta_{C_{3} A} \cdot \frac{1-\exp \left[A \cdot \tan ^{-1}\left\{B \cdot(w / b)^{C} \cdot t\right\}\right]}{\left.1+\exp \left[\left\{D \cdot(w / b)^{3}+E \cdot(w / b)^{2}+F \cdot(w / b)+G\right)\right\} \cdot \tan ^{-1}(H \cdot t)\right]} \times 100 \\
\alpha_{C_{3} S}(t)=\eta_{C_{3} S} \cdot \frac{1-\exp \left[\{A /(B+\exp (C \cdot w / b))\} \cdot \tan ^{-1}\{D \cdot t\}\right]}{\left.1+\exp \left[\left\{E \cdot(w / b)^{3}+F \cdot(w / b)^{2}+G \cdot(w / b)+H\right)\right\} \cdot t^{\{I /(J+\exp (K \cdot w / b))\}}\right]} \times 100 \\
\alpha_{C_{4} A F}(t)=\frac{1-\exp \left[\{A /(B+\exp (C \cdot w / b))\} \cdot \tan ^{-1}\left\{D \cdot(w / b)^{E} \cdot t\right\}\right]}{\left.1+\exp \left[\left\{D \cdot(w / b)^{3}+E \cdot(w / b)^{2}+F \cdot(w / b)+G\right)\right\} \cdot \tan ^{-1}\left(H \cdot(w / b)^{I} \cdot t\right)\right]} \times 100 \\
\eta_{C_{3} S}=0.2 \alpha_{C_{3} S}(t-1)^{4}-0.4 \alpha_{C_{3} S}(t-1)^{3}+0.2 \alpha_{C_{3} S}(t-1)^{2}-0.05 \alpha_{C_{3} S}(t-1)+\left(\left(\frac{w}{b} \times \frac{W_{c}+W_{f}}{U W}\right)+0.97\right) \\
\eta_{C_{3} A}=-0.18 \alpha_{C_{3} A}(t-1)^{4}+0.24 \alpha_{C_{3} A}(t-1)^{3}-0.15 \alpha_{C_{3} A}(t-1)^{2}+0.01 \alpha_{C_{3} A}(t-1)+\left(\left(\frac{w}{b} \times \frac{W_{c}+W_{f}}{U W}\right)+1\right.
\end{gathered}
$$

where $\alpha_{C_{3} A}(t), \alpha_{C_{3} S}(t), \alpha_{C_{2} S}(t)$ and $\alpha_{C_{4} A F}(t)$ are degrees of hydration at the considered age of $C_{3} A, C_{3} S$, $C_{2} S$ and $C_{4} A F$, respectively (\%). $\alpha_{C_{3} A}(t-1)$ and $\alpha_{C_{3} S}(t-1)$ are degrees of hydration at the hour before the considered age of $C_{3} A$ and $C_{3} S(\%) . W_{c}$ and $W_{f}$ are the weights of cement and fly ash in a cubic meter of concrete, respectively $(\mathrm{kg})$. $U W$ is unit weight of concrete $\left(\mathrm{kg} / \mathrm{m}^{3}\right)$.

The degree of hydration increases with age of concrete and strongly depends on water to cement ratio $(\mathrm{w} / \mathrm{c})$. An increase in w/c value corresponds to an increase in the degree of hydration [23]. The cement hydration is more advanced when more water is available. Then, the degree of hydration of cement increases with an increase in $\mathrm{w} / \mathrm{c}$.

The degree of hydration of cement of concrete sample used in this study, obtained from Eq. (13), is shown in Fig. 1. The degrees of hydration of cement for mixture with $\mathrm{w} / \mathrm{c}=0.45$ are equal to 0.64 and 0.74 at 14 and 91 days, respectively. And the degrees of hydration of cement for mixture with $\mathrm{w} / \mathrm{c}=0.55$ are equal to 0.67 and 0.78 at 14 and 91 days, respectively. The obtained degrees of hydration were subsequently used to calculate mix proportion of concrete at different ages. It is obviously seen that the difference between degree of hydration of cement of sample at early age and that at full hydration $\left(\alpha_{h y}=\right.$ $100 \%$ ) is enlarged especially for mixture with low w/c. Hence, when the degree of hydration at full hydration of cement is used for calculation of mix proportion of hardened concrete especially at early age, it will result in a large inaccuracy when compared to that using time-dependent degree of hydration. 


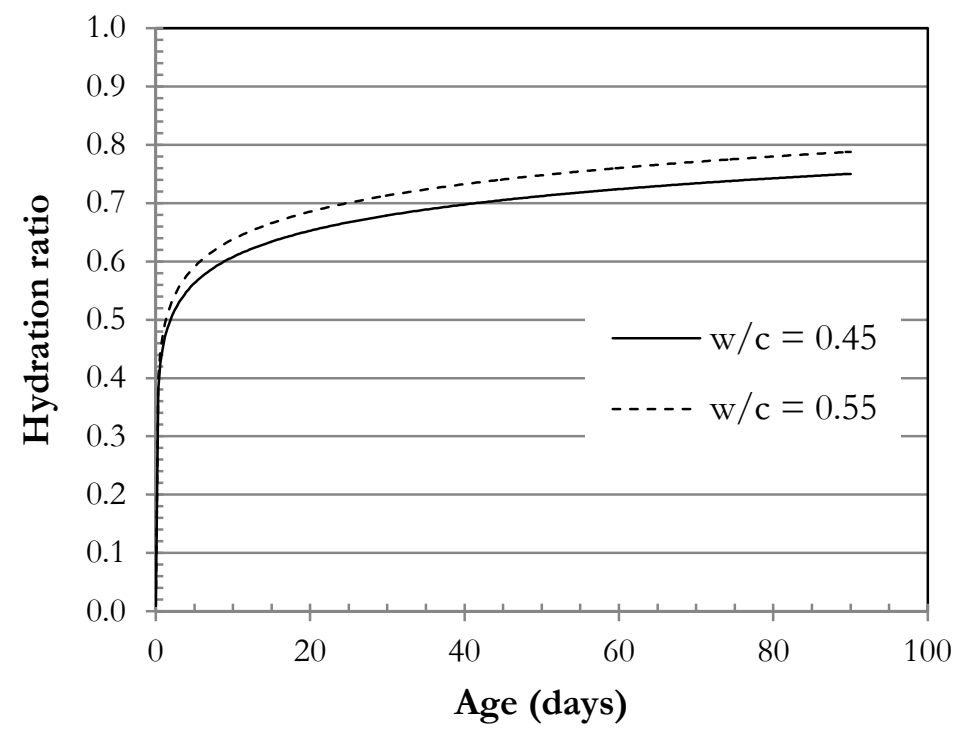

Fig. 1. Degree of hydration of cement of concrete samples with water to cement ratios of 0.45 and 0.55 .

\section{Results and Discussion}

\subsection{Selective Dissolution Test}

Residual weights of materials and concrete samples by selective dissolution method are shown in Table 3 and Table 4, respectively. It can be seen that cement is almost completely dissolved while sand is mostly insoluble. The residual weights of materials and concrete samples are subsequently used to calculate mix proportion of concrete for both with and without consideration of degree of hydration of cement. It is noted that the residual weights of each sample, as shown in Tables 3 and 4, are average values of three selective dissolution tests. It can be seen that the standard deviation of each three test results is very small. The standard deviations of the test results of cement and sand are 0.380 and 0.200 , respectively. The standard deviations of the test results of W45C at 14 and 91 days are 0.149 and 0.348 , respectively. And those of W55C at 14 and 91 days are 0.185 and 0.045 , respectively.

Table 3. Residual weights of concrete materials by selective dissolution method.

\begin{tabular}{ccc}
\hline Materials & Residue (\%) & $\begin{array}{c}\text { Standard } \\
\text { deviation }\end{array}$ \\
\hline Cement & 0.417 & 0.380 \\
Sand & 96.671 & 0.200 \\
\hline
\end{tabular}

Table 4. Residual weights of samples by selective dissolution method.

\begin{tabular}{ccccc}
\hline \multirow{2}{*}{ Sample } & \multicolumn{2}{c}{ Residue (\%) } & \multicolumn{2}{c}{ Standard deviation } \\
\cline { 2 - 5 } & 14 days & $\mathbf{9 1}$ days & 14 days & 91 days \\
\hline W45C & 61.374 & 60.965 & 0.149 & 0.348 \\
W55C & 64.380 & 64.011 & 0.185 & 0.045 \\
\hline
\end{tabular}

\subsection{Determination of Mix Proportion of Hardened Concrete}

The proposed mass balance equations were applied to estimate mix proportions of concrete prepared in laboratory with known mix design in order to verify the efficiency. The designed values of coarse aggregate content and $\mathrm{w} / \mathrm{c}$ were used in the analysis in addition to the results obtained from the selective dissolution test. The calculation of mix proportion of hardened concrete with and without consideration of timedependent degree of hydration $\left(\alpha_{h y}\right)$ are explored as follows. 
4.2.1. Calculation of mix proportion of hardened concrete without consideration of $\alpha_{h y}$

The calculation of mix proportion of hardened concrete without consideration of time-dependent degree of hydration was performed by applying degree of hydration equal to 1 for both ages at 14 days and 91 days in the analysis. The analytical results of mix proportion and error percentages are shown in Tables 5 and 7 , respectively. It is shown that the percentage of error of both samples W45C and W55C at 14 days is higher than that at 91 days. The maximum error of the determination of contents of cement and sand are 6.51 and 6.81 , respectively.

Table 5. Analytical results of mix proportion of concrete samples without consideration of $\alpha_{h y}$.

\begin{tabular}{|c|c|c|c|c|c|c|}
\hline Sample & $\begin{array}{c}\text { Age } \\
\text { (days) }\end{array}$ & $\mathrm{w} / \mathrm{c}$ & $\begin{array}{l}\text { Cement } \\
\left(\mathrm{kg} / \mathrm{m}^{3}\right)\end{array}$ & $\begin{array}{c}\text { Water } \\
\left(\mathrm{kg} / \mathrm{m}^{3}\right)\end{array}$ & $\begin{array}{c}\text { Sand } \\
\left(\mathrm{kg} / \mathrm{m}^{3}\right)\end{array}$ & $\begin{array}{c}\text { Coarse aggregate } \\
\left(\mathrm{kg} / \mathrm{m}^{3}\right)\end{array}$ \\
\hline \multirow{2}{*}{ W45C } & 14 days & 0.45 & 383 & 172 & 823 & 1025 \\
\hline & 91 days & 0.45 & 387 & 174 & 815 & 1025 \\
\hline \multirow{2}{*}{ W55C } & 14 days & 0.55 & 336 & 185 & 828 & 1025 \\
\hline & 91 days & 0.55 & 339 & 187 & 822 & 1025 \\
\hline
\end{tabular}

4.2.2. Calculation of mix proportion of hardened concrete with consideration of $\alpha_{h y}$

The mix proportion of hardened concrete was calculated with consideration the effect of age of sample by taking into account the time-dependent degree of hydration (Eqs. (13) to (19)) in the analysis. The degrees of hydration used in the calculation are equal to 0.64 and 0.74 for mixture with w/c $=0.45$ at 14 and 91 days, respectively. For mixture with w/c $=0.55$, the degrees of hydration of 0.67 and 0.78 , were used for concrete at 14 and 91 days, respectively. The analytical results of mix proportion and the error percentages are shown in Tables 6 and 7, respectively. It can be seen that the proposed calculation method can be used to determine mix proportion of hardened concrete with satisfactory accuracy for both sample W45C and W55C at 14 and 91 days. The estimated mix proportion of concrete at 14 days is almost identical to that at 91 days for both W45C and W55C. The maximum errors of the determination of content of cement and sand are 3.63 and 3.80, respectively. The error percentages of mix proportion of concrete samples at 14 and 91 days are less than 5\%, proving a high precision for estimation of the proposed method. The analytical results obtained by the proposed method were compared with those obtained by other research works [1, 3, $5,10]$. It was found that the error percentages of the analytical results obtained by the proposed method were mostly smaller than those of the others.

Moreover, it is remarkably seen that the calculation of mix proportion of hardened concrete with consideration of time-dependent degree of hydration provides less error than that without consideration of the degree of hydration as shown in Table 7. The proposed mass balance equations together with the timedependent degree of hydration can be used to precisely estimate mix proportion of concrete for both early age and later age. The error percentages of analytical results by the proposed equations with consideration of time-dependent degree of hydration are smaller than that without consideration of the degree of hydration by about 59\% and 49\% for mixture with w/c $=0.45$ (W45C) at 14 and 91 days, respectively. For mixture with $\mathrm{w} / \mathrm{c}=0.55$ (W55C) at 14 and 91 days, the error percentages of analytical results with consideration of time-dependent degree of hydration are smaller than that without consideration of the degree of hydration by about $48 \%$ and $36 \%$, respectively. The calculation with consideration of timedependent degree of hydration leads to a more precise mix proportion estimation and more effective for estimation at early age especially for mixtures with lower w/c because the difference between degree of hydration of cement of sample at early age and that at full hydration $\left(\alpha_{h y}=100 \%\right)$ is more enlarged especially for mixture with low w/c. Therefore, it is confirmed that effect of age of concrete on determination of mix proportion of hardened concrete can be covered by taking into account the timedependent degree of hydration in the analysis. 
Table 6. Analytical results of mix proportion of concrete sample with consideration of $\alpha_{h y}$.

\begin{tabular}{ccccccc}
\hline Sample & $\begin{array}{c}\text { Age } \\
\text { (days) }\end{array}$ & w/c & $\begin{array}{c}\text { Cement } \\
\left(\mathbf{k g} / \mathbf{m}^{\mathbf{3}}\right)\end{array}$ & $\begin{array}{c}\text { Water } \\
\left(\mathbf{k g} / \mathbf{m}^{3}\right)\end{array}$ & $\begin{array}{c}\text { Sand } \\
\left(\mathbf{k g} / \mathbf{m}^{3}\right)\end{array}$ & $\begin{array}{c}\text { Coarse aggregate } \\
\left(\mathbf{k g} / \mathbf{m}^{3}\right)\end{array}$ \\
\hline \multirow{2}{*}{ W45C } & 14 days & 0.45 & 397 & 179 & 795 & 1025 \\
& 91 days & 0.45 & 396 & 178 & 796 & 1025 \\
\hline \multirow{2}{*}{ W55C } & 14 days & 0.55 & 347 & 191 & 803 & 1025 \\
& 91 days & 0.55 & 347 & 191 & 805 & 1025 \\
\hline
\end{tabular}

Table 7. Error percentages of analytical results by the proposed equations.

\begin{tabular}{|c|c|c|c|c|c|c|c|}
\hline \multirow{2}{*}{ Sample } & \multirow{2}{*}{$\begin{array}{c}\text { Age } \\
\text { (days) }\end{array}$} & \multicolumn{3}{|c|}{ Without Considering $\alpha_{h y}{ }^{*}$} & \multicolumn{3}{|c|}{ With Considering $\alpha_{h y}{ }^{* *}$} \\
\hline & & Cement & Water & Sand & Cement & Water & Sand \\
\hline \multirow{2}{*}{ W45C } & 14 & -5.80 & -5.80 & +6.06 & -2.38 & -2.38 & +2.49 \\
\hline & 91 & -4.91 & -4.90 & +5.13 & -2.49 & -2.48 & +2.60 \\
\hline \multirow{2}{*}{ W55C } & 14 & -6.51 & -6.51 & +6.81 & -3.39 & -3.39 & +3.55 \\
\hline & 91 & -5.67 & -5.67 & +5.94 & -3.63 & -3.63 & +3.80 \\
\hline
\end{tabular}

Note: - and + mean underestimate and overestimate, respectively.

* Degree of bydration at full bydration $\left(\alpha_{h y}=1\right)$

** Time-dependent degree of bydration ( $\alpha_{h y}$ at 14 and 91 days)

\section{Conclusions}

A method for estimating mix proportion of hardened OPC concrete was proposed in this study. A set of mass balance equations was formed to calculate content of concrete compositions. The degree of hydration of cement was taken into account in the analysis in order to cover the effect of age of concrete. The proposed method was applied to determine mix proportion of concrete prepared in the laboratory with known mix design in order to verify its accuracy. From the analytical results, it was found that the proposed method could be used to precisely estimate mix proportion of concrete with two tested water to binder ratios at 14 and 91 days of age of concrete. The estimated mix proportion of concrete at 14 days is almost identical to that at 91 days. The error percentages of the mix proportion prediction of the concrete samples was less than $5 \%$. The calculation of mix proportion of hardened concrete with consideration of timedependent degree of hydration showed smaller errors than that without consideration of the degree of hydration. This can be confirmed that effect of age of concrete on determination of mix proportion of hardened concrete can be covered by taking into account the time-dependent degree of hydration in the analysis.

\section{Acknowledgement}

The authors would like to gratefully acknowledge the research scholarship of CHE \& AUN/SEED Net project with contract no. of CA3/2553 from Faculty of Engineering, Burapha University, Thailand. The research is also partially supported by the Higher Education Research Promotion and National Research University Project of Thailand, Office of the Higher Education Commission, the Thailand Research Fund (Grant No. TRG5380015) and the Center of Excellence in Material Science, Construction and Maintenance Technology, Thammasat University.

\section{References}

[1] L. Linares, M. Lopez-Atalaya, and S. Chinchon, "Cement content determination through selective stain in hardened concrete," Cement and Concrete Research, vol. 39, no. 11, pp. 1105-1109, Nov. 2009.

[2] Standard test method for portland-cement content of hardened bydraulic-cement concrete, ASTM C1084-02, American Society for Testing and Materials, 2002.

[3] G. G. Clemena, "Determination of the cement content of hardened concrete by selective solution," Virginia Highway Research Council, Sept. 1972. 
[4] H. S. Wong and N. R. Buenfeld, "Determining the water-cement ratio, cement content, water content and degree of hydration of hardened cement paste: Method development and validation on paste samples," Cement and Concrete Research, vol. 39, pp. 957-966, 2009.

[5] H. S. Wong, N. R. Buenfeld, and K. Matter, "Estimating the original cement content and watercement ratio (w/c) of Portland cement concrete and mortar using backscattered electron microscopy," Magazine of Concrete Research, vol. 65, no. 11, pp. 639-706, May 2013.

[6] S. Sahu, S. Badger, and N. Thaulow, "Determination of water-cement ratio of hardened concrete by scanning electron microscopy," Cement and Concrete Research, vol. 26, no. 8, pp. 987-992, Nov. 2004.

[7] T. P. Philippidis and D. G. Aggelis, "An acousto-ultrasonic approach for the determination of waterto-cement ratio in concrete," Cement and Concrete Research, vol. 33, no. 4, pp. 525-538, Apr. 2003.

[8] J. Elsen, N. Lens, T. Aarre, D. Quenard, and V. Smolej, "Determination of the w/c ratio of hardened cement paste and concrete sample on thin sections using automated image analysis techniques," Cement and Concrete Research, vol. 25, no. 4, pp. 827-834, 1995.

[9] Methods for analysis of hardened concrete, BS1881: Part24, British Standards Institution, 1998.

[10] M. S. Jung, M. C. Shin, and K. Y. Ann, "Fingerprinting of a concrete mix proportion using the acid neutralisation capacity of concrete matrices," Construction and Building Materials, vol. 26, no. 1, pp. 6571, Jan. 2012.

[11] Standard practice for making and curing concrete test specimens in the laboratory, ASTM C192-02, American Society for Testing and Materials, 2002.

[12] Standard test Method for density, absorption, and voids in hardened concrete, ASTM C642-06, American Society for Testing and Materials, 2006.

[13] S. Ohsawa, K. Asaga, S. Goto, and M. Daimon, "Quantitative determination of fly ash in the hydrated fly ash- $\mathrm{CaSO}_{4} \cdot 2 \mathrm{H}_{2} \mathrm{O}-\mathrm{Ca}(\mathrm{OH})_{2}$ system", Cement and Concrete Research, vol. 15, no. 2, pp. 357-366, Mar. 1985.

[14] FACOMP, Sirindhorn International Institute of Technology (SIIT), Thammasat University, Thailand.

[15] L. V. Hung and S. Tangtermsirikul, "A strength model for no-slump concrete with fly ash,", Magazine of Concrete Research, vol. 59, no. 3, pp. 211-221, Apr. 2007.

[16] S. Tangtermsirikul, T. Kaewkhluab, and P. Jitvutikrai. "A compressive strength model for rollercompacted concrete with fly ash," Magazine of Concrete Research, vol. 56, no. 1, pp. 35-44, Feb. 2004.

[17] T. Chuosavasdi, W. Saengsoy, B. Stitmannaithum, T. Sumranwanich, and S. Tangtermsirikul, "Determination of mix proportion of hardened OPC concrete," in Proc. The 19th National Convention on Ciwil Engineering, Khon-Kaen, Thailand, pp. 670-675, May 2014.

[18] J. I. Escalante-Garcia, "Nonevaporable water from neat OPC and replacement materials in composite cements hydrated at different temperatures," Cement and Concrete Research, vol. 33, no 11, pp. 1883 1888, Nov. 2003.

[19] H. F. W. Taylor, Cement Chemistry. Academic Press London, 1990.

[20] S. Tangtermsirikul and W. Saengsoy, "Simulation of free water content of paste with fly ash," Research and Development Journal of the Engineering Institute of Thailand, vol. 13, no. 4, pp. 1-10. 2002.

[21] W. Saengsoy, "Simulation of thermal properties and adiabatic temperature rise of fly ash concrete," M.S. thesis, Sirindhorn International Institute of Technology, Thammasat University, Thailand, 2002.

[22] P. Choktaweekarn, "Thermal properties and model for predicting temperature and thermal cracking in mass concrete," Ph.D. thesis, Sirindhorn International Institute of Technology, Thammasat University, Thailand, 2008.

[23] L. Lam, Y. L. Wong, and C. S. Poon, "Degree of hydration and gel/space ratio of high-volume fly ash/cement systems," Cement and Concrete Research, vol. 30, no. 5, pp. 747-756, May 2000. 